\title{
A Review: Experimental Investigation of an Air Conditioning System by Using Different Alloy Material for Condenser
}

\author{
Dipak H. Deore ${ }^{1}$, Prof. M.P.Thakur ${ }^{2}$, Prof. T.A.Koli ${ }^{3}$ \\ ${ }^{I}$ M.E. Thermal engineering student, GF's Godavari College of Engineering, Jalgaon. \\ ${ }^{2}$ Assistant Professor Department of Mechanical Engineering, GF's Godavari College of Engineering, Jalgaon. \\ ${ }^{3}$ H.O.D. Department of Mechanical Engineering, GF's Godavari College of Engineering, Jalgaon.
}

\begin{abstract}
Energy saving is the practice of decreasing the quantity of energy used. It may be achieved through efficient energy use or by reducing the consumption of energy services. Air conditioning units are usually used for small and medium scale residential buildings. The amount of energy consumed by air conditioners, refrigerators and water heaters is increasing rapidly, since the consumed power by air conditioners occupies about $20 \%$ of the total power consumption. The improvement of refrigeration cycle performance can be done by lowering the compressor power consumption, increasing the condenser heat rejection capacity or reducing the difference between condenser and evaporator pressures. The aim of this project is to experimentally improve the coefficient of performance of air conditioning system by using different alloying material for condenser.
\end{abstract}

.Keywords- Condenser, Material considered aluminum LM 304 and LM311 for copper L100.

\section{I- INTRODUCTION}

$\mathbf{R}$ duction of energy consumption is a major concern in vapour compression cooling systems, especially in areas with very hot weather conditions. In hot weather conditions, performance of these systems decrease sharply and electrical power increases considerably. Evaporative condensers enhance the heat rejection process by using the cooling effect of evaporation and therefore improve energy-usage efficiency. This paper presents an extensive review of the state of the art of evaporative condensers used in residential cooling systems: refrigeration, air-conditioning, and heat pump systems. The paper primarily concentrates on the energy consumption of residential cooling systems worldwide and its related problems. In addition, the paper covers the operation principles of evaporative-condensers, theory of heat rejection, and water evaporation rate. Finally, comparison between different types of condensers is presented. It is found that by using evaporative-cooled condenser instead of air-cooled condenser, the power consumption can be reduced up to $58 \%$ and the coefficient of performance can be improved by about $113.4 \%$ with systems of different cooling capacities ranging from 3 to $3000 \mathrm{~kW}$.

\section{II- LITERATURE REVIEW}




\section{International Journal of Innovations in Engineering and Science, www.ijies.net}

\section{Thermal Exchange In Human Body-}

The Human Body Works Best At Certain Temperatures Like Other Machines, But It Cannot Tolerate With Range Of Variations. The Human Body Maintains Its Thermal Equilibrium By Three Modes Of Heat Transfer I.E. Evaporation, Radiation And Convection. A Human Body Feels Comfortable When The Heat Produced By Metabolism Of Human Body Is Equal To The Sum Of Heat Dissipated To The Surroundings. The Normal Temperature Of The Human Body Is 37 Degree Centigrade Or 98.6 Degree Fahrenheit. But, If This Level Goes Below 36.5 Degree Centigrade Or 98 Degree Fahrenheit And Exceeds 40.5 Degree Centigrade Or 105 Degree Fahrenheit, The Conditions Become Dangerous For Human Existence.

\section{FACTORS AFFECTING HuMAn COMFORT-}

The Important Factors While Designing Any System Of Comfort Are

- $\quad$ Effective Temperature

- Heat Production \& Regulation In Human Body

- Heat And Moisture Losses From Body

- Moisture Content Of Air

- Quality And Quantity Of Air

- Air Motion

- Air Stratification

Physiological Hazards Resulting From Heat And Extreme Cold Are

- Heat Cramp

- Heat Stroke

- Frost Bites

- Hypothermia

- Hyperthermia

\section{III-VAPOUR COMPRESSION}

\section{Refrigeration Cycle}

The low pressure vapor in dry state is drawn from the evaporator during the suction stroke of the compressor. During compression stroke the pressure and temperature increases until the vapor temperature is greater than the temperature of condenser cooling medium.

\section{Condensation}

When the high pressure refrigerant vapour enters the condenser heat flows from condenser to cooling medium thus allowing vaporized refrigerant to return to liquid state

\section{Expansion}

After condenser the liquid refrigerant is stored in the liquid receives until needed. From the receiver it passes through an expansion value where the pressure is reduced sufficiently to allow the vaporization of liquid at a low temperature of about - 10 degree centigrade.

\section{Vaporization}

The low pressure refrigerant vapor after expansion in the expansion valve enters the evaporator on refrigerated space where a considerable amount of heat is absorbed by it and refrigeration is furnished

\section{IV- ADVANTAGES AND DISADVANTAGES OF VAPOUR COMPRESSION REFRIGERATION SYSTEM OVER AIR REFRIGERATION SYSTEM}

\section{Advantages}

- The Coefficient Of Performance Is Quite High As The Working Cycle Of This System Is Near The Carnot Cycle

- The Among Of Refrigerant Circulated Is Less Per Ton Of Refrigeration Than Air Refrigeration System Because The Heat Carried Away By The Refrigerant Is The Latent Heat. As A Result Of This, The Size Of Evaporator Is Smaller For The Same Refrigerating Effect.

- This System Can Be Employed Over A Large Range Of Temperatures. By Adjusting The Expansion Valve of The Same Unit, The Required Temperature In The Evaporator Can Be Achieved.

- The Running Cost Of This System Is Less Than Air Refrigerating System. The Air Refrigeration System Requires Five Times More Power Than A Vapor Compression Refrigeration System Of The Same Capacity.

\section{Disadvantages}

- $\quad$ Prevention Of Leakage Of Refrigerant In This System Is The Major Problem. First Investment Cost Is High Than The Air Refrigeration System.

\section{REFERENCES}

[1] C.F. Gao; W.L. Lee; And Hua Chen; Locating Room Air-Conditioners At Floor Level For Energy Saving 
In Residential Buildings; Applied Thermal Engineering; 29; Issues 2-3; 2009; Pp. 310-316.

[2] E. Hajidavalloo; H. Eghtedari; Performance Improvement Of Air-Cooled Refrigeration System By Using Evaporatively Cooled Air Condenser; Int. Journal Of Refrigeration; 33; Issue 5; 2010; Pp. 982-988. Doi: 10.1016/J.Ijrefrig.2010.02.001.

[3] Zhenjun Xu; Huaizhi Wu; Meiling Wu; Energy Performance And Consumption For Biogas Heat Pump Air Conditioner; Energy; 35; Issue 12; 2010; Pp. 5497-5502.

[4] A. Benamer; D. Clodic; Comparison Of Energy Efficiency Between Variable And Fixed Speed Scroll Compressors In Refrigeration System; Proceedings of Technological Innovations In Refrigeration In Air Conditioning And In The Food Industry Into Third Millennium; 8th-9 June; 1999; Pp.1-8.

[5] S.S. Hu; B.J. Huang; Study Of A High Efficiency Residential Split Water-Cooled Air Conditioner; Applied Thermal Engineering; 25; 2005; Pp. 15991613. Doi: 10.1016/J.Applthermaleng.2004.11.011.

[6] S. Wang; Z. Liu; Y. Li; K. Zhao And Z. Wang; Experimental Study On Split Air Conditioner With New Hybrid Equipment Of Energy Storage And Water Heater All Year Round; Energy Conversion And Management; 46; 2005; Pp. 3047-3059. Doi: 10.1016/J.Enconman.2004.10.024.

[7] F.W. Yu And K.T. Chan; Advanced Control Of Heat Rejection Airflow For Improving The Coefficient Of Performance of Air Cooled Chillers; Applied Thermal Engineering; 26; 2006; Pp. 97-110. Doi: 10.1016/J.Applthermaleng.2005.04.014.

[8] H. Chen; W.L. Lee And F.W. Yik; Applying Water Cooled Air Conditioners In Residential Buildings In Hong Kong; Energy Conversion And Management; 49; 2008; Pp. 1416-1423. Doi: 10.1016/J.Enconman.2007.12.024.

[9] T. Mahlia And R. Saidur; A Review On Test Procedure Energy Efficiency Standards And Energy Labels For Room Air Conditioners And RefrigeratorFreezers; Renewable And Sustainable Energy Reviews; 14; Issue 7; 2010; Pp. 1888-1900. Doi: 10.1016/J.Rser.2010.03.037.

[10] M. L. Jiang; J. Yi Wu; Y. X. Xu And R. Z. Wang; Transient Characteristics And Performance Analysis Of A Vapor Compression Air Conditioning System With Condensing Heat Recovery; Energy And Buildings; 42; Issue 11; 2010; Pp. 2251-2257. Doi: 10.1016/J.Enbuild.2010.07.021. 